\title{
Conical picks of mining machines with increased utility properties - selected construction and technological aspects
}

\author{
Piotr CHELUSZKA ${ }^{1 *}$, Stanistaw MIKUŁA $A^{2}$ and Jarostaw MIKUŁA ${ }^{3}$
}

\begin{abstract}
Authors' affiliations and addresses:
${ }^{1}$ Department of Mining Mechanization and

Robotisation, Faculty of Mining, Safety

Engineering and Industrial Automation Silesian

University of Technology, Akademicka 2, 44-100

Gliwice, Poland,

e-mail Piotr.Cheluszka@polsl.pl
\end{abstract}

${ }^{2}$ Retired researcher at the Department of Mining Mechanization and Robotisation, Faculty of Mining, Safety Engineering and Industrial Automation Silesian University of Technology, Akademicka 2, 44-100 Gliwice, Poland,

${ }^{3}$ Department of Engineering Materials and Biomaterials, Faculty of Mechanical Engineering, Silesian University of Technology, Konarskiego

18a, 44-100 Gliwice, Poland,

e-mail Jaroslaw.Mikula@polsl.pl

*Correspondence:

Piotr Cheluszka, Department of Mining

Mechanization and Robotisation, Faculty of

Mining, Safety Engineering and Industrial

Automation Silesian University of Technology,

Akademicka 2, 44-100 Gliwice, Poland,

tel: +48 322372256

e-mail: Piotr.Cheluszka@polsl.pl

Funding information:

Funding Agency: Polish National Centre for

Research and Development

Grant Number: PBS3/B2/15/2015

\section{Acknowledgement:}

The work has been implemented under the research project titled "Control of roadheader cutting heads movement for the reduction of energy consumption of mining and dynamic loads" co-financed by the Polish National Centre for Research and Development under the Applied Research Projects (agreement no. PBS3/B2/15/2015).

How to cite this article:

Cheluszka, P., Mikuła, S. and Mikuła, J. (2021). Conical picks of mining machines with increased utility properties - selected construction and technological aspects. Acta Montanistica Slovaca. Volume 26 (2) 195-204

DOI:

https://doi.org/10.46544/AMS.v26i2.02

\begin{abstract}
Shearers and roadheaders are commonly used to extract useful mineral deposits, especially hard coal, and for drilling roadways in underground mines, tunnels and other underground buildings in civil engineering. As the primary working process of this type of machines, mechanical mining of rocks is carried out by cutting. These machines' working units are equipped for this purpose with picks, usually conical (point-attack). They have the form of an axially symmetrical body consisting of a steel shaft and a tip usually made of tungsten carbide, connected by a hard brass solder. Due to the possibility of spontaneous rotation in the pick holders and even wear and tear of their tip around the entire perimeter, conical picks have a much longer service life compared to radial picks. Their life, especially when cutting hard and sharp abrasive rocks, is, however, still unsatisfactory. Rapid wear of the picks leads to a decrease in mining efficiency, an increase in this process's energy consumption, and an increase in dynamic surplus to which the cutting machine is subject. Among many forms of wear and tear of the conical picks, attention was paid to the problem of asymmetrical abrasive wear of the tips, pulling out the connection of the soldered pick tip and fatigue breaking of the pick shafts in the transition zone of the shank into the shoulder. The article presents original propositions of modification of the construction of the roadheaders/shearers conical pick shafts and the method of fixing the tip in the pick shaft in order to increase their operational durability significantly. The technologies and devices necessary to manufacture conical picks of the proposed structure were described. The developed modifications significantly contribute to the improvement of functional properties, including the reliability of conical picks, used in particular for hard rock mining.
\end{abstract}

\section{Keywords}

conical picks of mining machines, wear and tear, modification of the construction, manufacturing technology, improvement of durability 


\section{Introduction}

Modern longwall shearers used for mining coal and other minerals mined in longwall systems, as well as roadheaders used for drilling roadways in underground mines, tunnels and other underground buildings, are commonly equipped with conical (point-attack) picks armed with tips usually made of tungsten carbides (Fig. 1a $\&$ b). They have the form of axially symmetrical rotary elements embedded in pick holders attached by welding to the side surface of the cutting drums/heads of various shapes and sizes, depending on the purpose. There are often special, exchangeable sleeves made of alloy steel and heat-treated between the pick holders and the conical picks to obtain increased resistance to contact pressure and abrasive and erosive wear (Fig. 1c).

a)

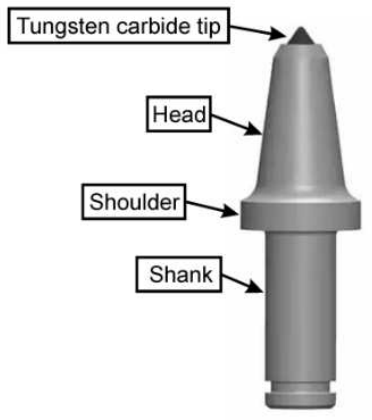

b)

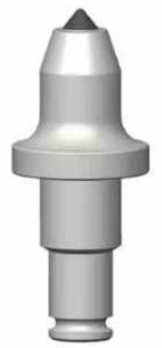

c)

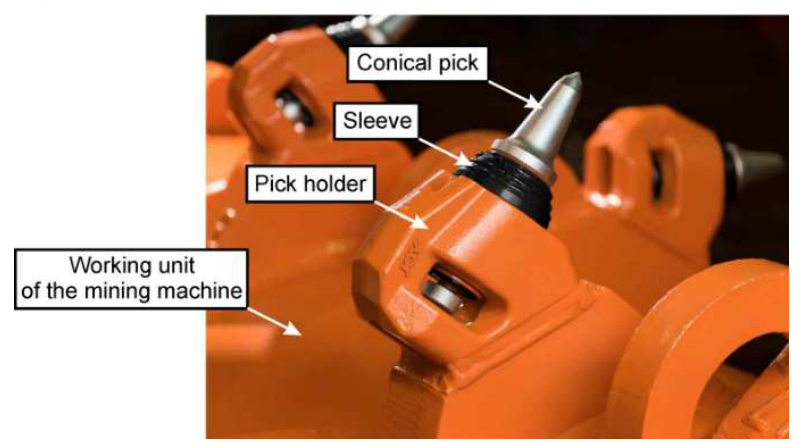

Fig. 1. Conical (point-attack) pick: a) U85/U85HD with a single shank (https://www.jyfmachinery.com/product/u85-u85hd-style-cuttingpicks-fitting-underground-mining-and-surface-mining, 2020), b) TS30C with a stepped shank (https://www.jyfmachinery.com/product/ts30ccutting-picks-fitting-underground-mining-and-surface-mining, 2020), c) mounted in a pick holder equipped with a sleeve (Komatsu, 2020)

Conical picks are characterized by high efficiency because during cutting; they are automatically rotated relative to their axes, which ensures regular wear of their head, especially the tips. Thanks to this, there is a kind of "self-sharpening" of the picks. This allows for an increased service life of the picks and reduction of mining energy consumption (Jonak, 1998; Liu et al., 2015; Dewangan and Chattopadhyaya, 2016).

In mining shearers/roadheaders operating conditions, there is often a disruption in the picks rotation process, which is influenced by many different factors. Dust, especially stone dust, in combination with water used to spray the mining zone creates a mixture, which often as a result of evaporation of water, sharply accelerated by heating of picks during work, tends to solidify. Deposits of solidified dust filling the gaps between the pick shanks and the slots in the pick holders make it difficult and, over time, prevent the picks from rotating. Corrosion processes also block the rotation of the picks, as the corrosion products have a larger volume than the corroded material. These adverse phenomena are favouring by longer breaks in the work of mining machines.

Conical picks that lose their ability to rotate at an accelerated rate are destroyed. The wear of picks takes an unfavourable asymmetrical form, which deepens the process of pick degradation. Then, more often, chipping of the cemented carbide tip occurs, and even their complete removal from the head of the pick shaft (Dewangan et al., 2015; Liu et al., 2015; Dewangan and Chattopadhyaya, 2016). Then, the mining's energy consumption increases, the level of vibrations and there are large dynamic surpluses accelerating the destruction of mining machines drives and their body. Also, the temperature of the picks increases sharply, accelerating their destruction. It even melts the hard solder, with which the picks are embedded in the pick shafts (Fig. 2). The wear of the picks on the heads/drums of mining machines is not the same. It depends on the location of the given pick on the side surface of the working unit of the mining machine (Tiryaki, 2004). This is due to the unequal conditions of the cutting process carried out by individual picks and the path on which they are in contact with the mined rock. The impact of picks on the mined rock, along with abrasive wear, is also accompanied by many other forms of wear, 
such as adhesive wear, oxidation, micro fracturing, fatigue, thermal cracking, impact damage or chemical erosion (Singh et al., 2013; Sarwary and Hagan, 2015; Underground Mining, 2020).

a)

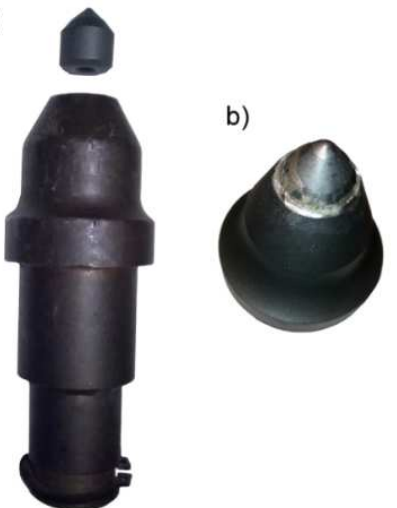

c)

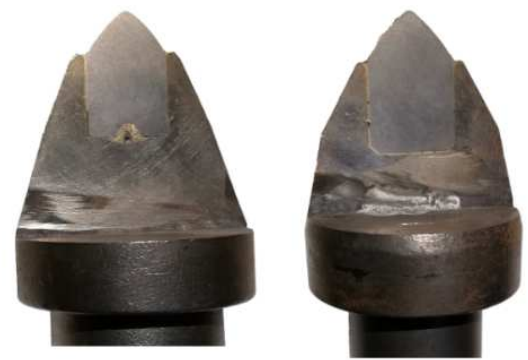

Fig. 2. The conventional method of fixing a tip in a conical pick shaft by brazing: a) components, b) view of a fixed cemented carbide tip, c) cross-section through a solder connection

In the situation described, solutions should be sought that favour the rotation of the picks in the pick holders and allow for more durable clamping of the tips in the conical pick shafts (Kotwica, 2010; Prokopenko et al., 2016; Choi et al., 2017; Bołoz, 2019).

Another type of operational damage to the conical picks $f$ the mining machines is fatigue fracture of the pick shanks (Luo et al., 2010; Lu et al., 2018) (Fig. 3). This type of destruction occurs less frequently than the symmetrical and asymmetrical wear of the head of the picks and breaking of the tips (in 70-80\% of cases, only the tips and the head of the picks are worn (Prokopenko et al., 2018)). However, these damages are more critical. The fatigue fracture effect is caused by the accumulation of stresses in the contact area of the shoulder with the pick holder caused by the action of digging forces and the occurrence of a geometric notch in the transition zone of shank into the shoulder of the pick. The direction of the resultant force from mining to the longitudinal axis of the pick is essential here (Park et al., 2018). The susceptibility to fatigue fracture of the pick is compounded, especially when there are large gaps in the pick seat in the pick holder. They may result from incorrectly selected tolerances for the diameter of the pick shank and the socket in the pick holder or excessive wear of the seat surface in the pick holder. After a fatigue fracture of the shank, which occurs suddenly and without previous symptoms, the picks immediately lose any ability to cut rocks. Very quickly, the pick holders are severely damaged. Removal of damage to the pick holders is associated with the need to remove and transport the cutting drum/head, usually to a repair shop. This results in a long-lasting stoppage of the shearer/roadheader, significant mining losses and high costs.

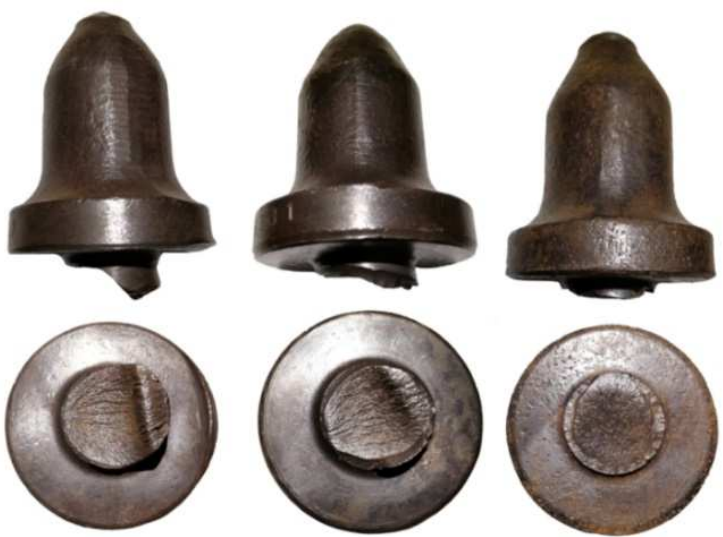

Fig. 3. Examples of the point-attack pick with low tip wear and fatigue broken shafts in the transition area between the shank and the shoulder

In the described situation, all possible material and technological solutions should be used to increase the fatigue life of conical pick shafts. One of the ways to achieve significant improvement in the fatigue life of pick shafts is to use surface crush in the form of static or dynamic burnishing (Cheluszka et al., 2019). The compressive stress formed in the surface layer due to burnishing treatment causes a delay in the initiation and inhibition of the growth of fatigue cracks, which results in a significant increase in the resistance of the picks to variable loads.

The problem of ensuring high durability of cutting tools used in mining machines is fundamental because the number of picks installed on the cutting heads/drums of these machines ranges on average from 40 to 60 , and in 
the case of roadheaders with transverse cutting heads, it can reach 90 (Gehring K H and Reumüller, 2002). This roadheader is therefore equipped with 180 picks. Also known are mining machines with unique construction, designed for mining hard and highly abrasive rocks (with compressive strength up to $120 \mathrm{MPa}$ ) in a longwall system. They are used to mine some types of platinum, copper and gold deposits. They are equipped with a much larger number of conical picks than those mentioned earlier (https://www.engineerlive.com/content/mining-hardrock-longwall-efficiency, 2020). They can be equipped with two arms located in a plane perpendicular to the face of the wall, each of which has two cutting heads. Each of these heads can be armed with 126 to 168 picks. As a result, the shearer can even be equipped with 672 picks (Rock Straight System, 2020). The costs of cutting tools, especially in the case of accelerated wear and tear, are therefore high.

Considering the above, R\&D works have been carried out for many years to increase the service life of mining machines picks. Increasingly better, more wear-resistant materials for tips, such as cemented carbides with an adequately selected structure (for example, S-Grade, Sandvik), tips with a multilayer structure (for example, Sandvik XT-Grade), thermostable diamond composites or ceramic materials (Restner et al., 2007; Jonak, 2011; Li et al., 2011; Prokopenko et al., 2016; Vogt, 2016; García et al., 2019). Additional technological measures are also applied to reduce the abrasive wear of the head of the pick shafts in the vicinity of the tip. Examples are the installation of cemented carbide rings, coating the surface with synthetic diamonds (PCD), the use of flat or round cemented carbide inserts, or hardening of the surface of the head of the pick shaft, e.g. by carburizing, laser, electric arc, HVOF or nanoHVOF (Bołoz, 2019; Choi et al., 2017; Krauze et al., 2016; Luo et al., 2010; Mu and Min, 2009). These treatments aim to reduce the intensity of wear of this part of the pick, which usually results in quick stripping of the tip and its pulling out of the mounting. The wear of the pick shaft's head does not have to be directly the result of the rock mining process but, for example, the friction of the pick against the spoil characterized by high abrasiveness and recirculation of this spoil (Underground Mining, 2020).

The article presents selected constructional and technological aspects of the manufacture of conical (pointattack) picks used especially for hard rock mining to improve their operational durability. Original proposals for modification of the conical picks structure, technological treatments and devices enabling their implementation on an industrial scale were presented. Apart from ensuring the possibility of achieving the goal mentioned above, the advantage of the developed modifications is low costs of their implementation. This is important for the economic profitability of their industrial use.

\section{Modification of the construction of the conical picks for mining machines}

The shank of the conical pick shafts usually has a cylindrical form with a constant diameter along the entire length of the shank (Fig. 1a) or with a graduated diameter with its increase in the transition zone into the pick's shoulder (Fig. 1b). The moment of resistance opposing the rotation of the picks around their axis (conditioning even wear of the tip along its entire circumference) is higher, the greater the radius of the shanks and the higher the average radius of the contact surface of the pick shoulder with the front surface of the pick holder (Kotwica, 2012). It would, therefore, be beneficial to use the smallest possible diameter of the shank and the smallest possible outer diameter of the shoulder to ensure rotation of the picks. In turn, to ensure sufficient resistance to contact pressure and resistance to abrasive wear, a large surface area and a large external diameter of the shoulder are desirable. Due to the high static and fatigue fracture strength of the pick shanks, their large diameter is required. Also, it is desirable to use the largest possible transition radius between the shank and the shoulder (Fig. 4) to minimize the harmful effect of the geometric notch in this zone of the pick. The described opposing requirements create difficulties in the selection of the most advantageous dimensions in the sensitive zone of mining machines picks.

For currently manufactured conical picks used in mining machines, the transition radius varies between 1.5 and about $5 \mathrm{~mm}$ with a predominance of smaller values. Meanwhile, applying the rules as in the case of grading the diameter of shafts, the transition radii in the set-off should be at least (Dąbrowski, 2013):

$$
R \geq 0.25 \cdot\left(D_{S L}-d_{S H}\right) ;[m m]
$$

where:

$R$ - transition radius between the shoulder and the shank of the pick shaft [mm],

$D_{S L}-$ shoulder diameter $[\mathrm{mm}]$,

$d_{S H}$ - diameter of the shank of the pick shaft [mm]. 


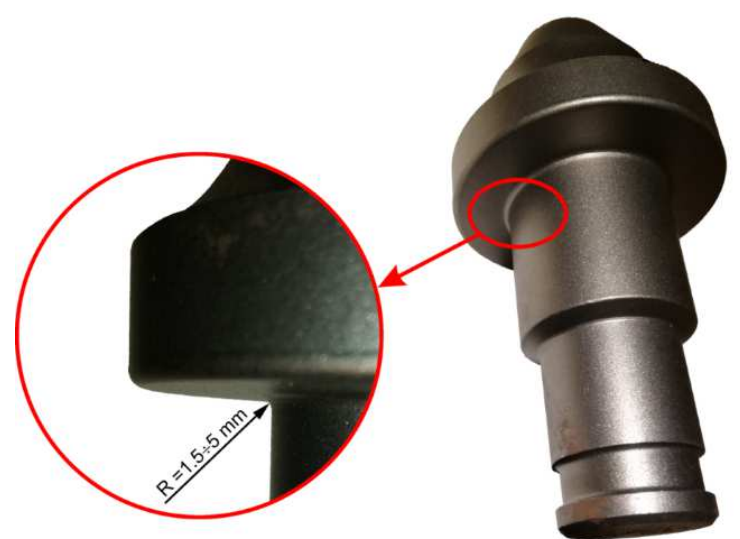

Fig. 4. View of the transition area between the shank and the shoulder of a typical conical pick

For example, for picks with a shank diameter of $\mathrm{d}_{S H}=38 \mathrm{~mm}$ and the shoulder diameter $D_{S L}$ from 52 to $65 \mathrm{~mm}$, the transition radius $R$ should be higher than $5 \div 7 \mathrm{~mm}$. In turn, for picks with a shank diameter $d_{S H}=30 \mathrm{~mm}$ and diameter of the shoulder diameter $D_{S L}$ from the range mentioned above, the transition radius $\mathrm{R}>6 \div 9 \mathrm{~mm}$.

One of the solutions facilitating the fulfilment of the requirements described above may be the use of adapter rings between the pick holder or sleeve and the bottom surface of the pick shaft shoulder. Such rings, made e.g. of alloy steel that has undergone heat or thermochemical treatment to achieve high hardness, allow effective reconciliation of the above-mentioned opposite requirements, especially when the picks are mounted in hardened sleeves. An exemplary shape of the adapter rings is illustrated in Fig. 5. The adapter rings enable the use of a larger radius of the transition of the pick shank into its shoulder and minimize its outer diameter. It is possible to use a fixed transition radius, as in Fig. 5a. A much more beneficial solution is to shape this pick zone with a variable radius $R$ (Fig. 5b) with the largest possible radius in the zone of transition into the shank of the pick shaft or to use a half-toroidal shape (Fig. 5c). This configuration allows obtaining the most effective reduction of the notch, contributing to the increase in fatigue life of the pick shafts.

The transition radius of the pick shafts, irrespective of the construction variant used, can be additionally strengthened by surface deformation carried out in one operation with burnishing of the shank. It is expedient here to protect this zone from corrosive influences, for example, by covering it with heat-resistant varnish. The use of a small angle $\beta$ the inclination of the abutment surface facilitates the removal of dust particles, intensifying abrasive and erosive wear and making it difficult for the spray water with dust suspension to get into the pick seat the pick holders (Fig. 5b).

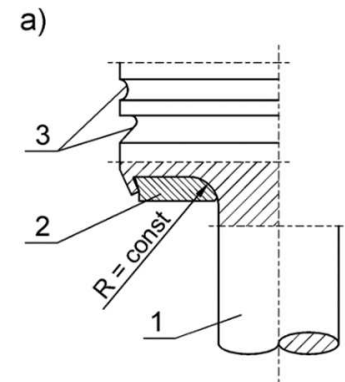

b)

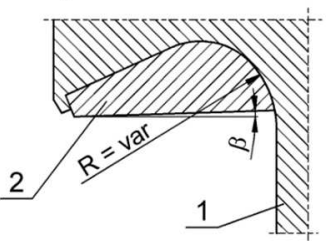

c)

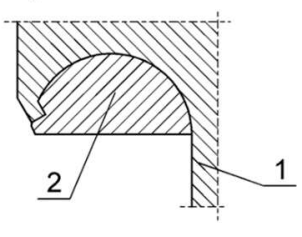

Fig. 5. Modification of the construction of the shaft of mining machines conical picks with adapter rings fixed by rolling the device from Fig. 6: a) adapter ring with constant radius $R=$ const, $b$ ) adapter ring with variable radius $R=$ var increasing towards the shank and with a bevel at an angle $\beta$ that facilitates the removal of dust and wear products from the friction area of the shoulder against the sleeve or pick holder, c) the half-toroidal adapter ring: 1 - shank of the pick, 2 -adapter ring, 3 -relief notches reducing stress concentration in the transition zone of the head of the pick into the shoulder

It is desirable to permanently seat the adapter rings in the pick shafts, which can be done, e.g. by rolling using the tool in Fig. 6. After placing the pick (1) in the socket (9) with the high-friction insert (6) and fixed in the base 
(3), the adapter ring (2) is inserted into the opening (1a) the shoulder (1b) from the shank (1c) of the pick shaft. Then the head (4) with the rollers (5) is lowered while giving it rotation about an axis (10) and longitudinal pressure until the edge part (7)of the pick is finally formed, as shown in Fig. 6c. Fig. 6b shows the condition before rolling the adapter ring. The rollers (5) are fixed in the head (4) using a cover (8). The head (4) can be rotated and pressed using a pillar drill, table drill or vertical milling machine. This procedure permanently connects the adapter ring to the pick shaft, which additionally protects the critical zone of the shaft, where fatigue fractures of pick shanks occur most often.

The conical picks with the described modification retain the same external dimensions as conventional picks, which allows their use in existing cutting heads/drums of mining machines.

Different types of sintered materials containing friction coefficient additives, such as graphite or molybdenum disulphide $\left(\mathrm{MoS}_{2}\right)$, can be used for the adapter rings to reduce drag when the picks rotate. The adapter rings may be rolled cold or with local heating, e.g. with high-frequency currents. The thermal cramp after the procedure additionally strengthens the obtained connection of the adapter rings with the pick shafts, regardless of the method of the procedure.

\section{Positive-fit fastening of cutting tips in conical pick shafts}

Commonly used fastening of cemented carbide tips in pick shanks by brazing (Fig. 2) often does not meet the operational requirements, especially in the case of hard rock mining. Tips under extreme conditions are subject to accelerated damage in the form of tips chipping and even their full extraction (Cheluszka et al., 2019). Large temperature gradients occurring when cutting hard, highly abrasive rocks lead to softening and sometimes even melting of hard, usually brass solder. The insufficient or incorrect sprinkling of the cutting zone and incorrectly selected cutting parameters contribute to this.

Figure 7 shows the method of fixing tips in conical picks shafts through a form-fit connection and a device for the practical implementation of the rolling process of tips (Cheluszka and Mikuła, 2019). This method consists of permanently setting the tip by hot rolling the material of the head of the pick shaft. The appropriate shape of the tip and its seating will ensure high operational durability of the connection with the simultaneous strengthening of the material of the head of the conical pick.

b)
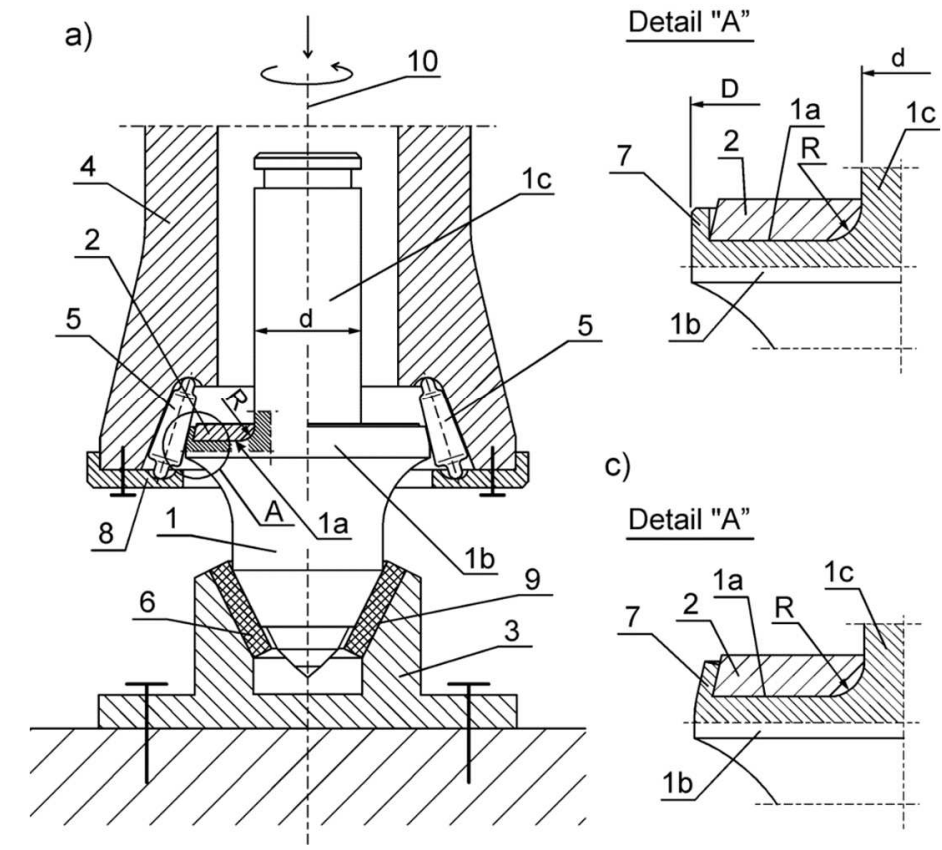

Fig. 6. Device for mounting adapter rings in the shafts of mining machines conical picks: a) the device when connecting the adapter ring (2) in the pick (1) by rolling the shoulder material, $b$ ) detail " $A$ " before the rolling operation, $c$ ) detail "A" after permanent rolling of the shoulder material (7) on the adapter ring (2) (description of the operation and indications of the device elements in the text)

The pick (1) that is being processed, which in the head (1a) of the shaft has a cylindrical seat (1b), is equipped with a tip (4) of cemented carbide. The tip should have a cross-section increasing towards the base. In the case of axially symmetrical tips, they can be in the form of a cone with a small angle of sidewall convergence. The tip is permanently connected to the head of the pick shaft by rolling using rollers (6) after preheating the material in the connection zone to softening temperature. Heating up can be carried out inductively or with a gas burner system. The rollers (6) are pressed to the pick by the head (5) set in rotary motion, e.g. using a bench or column drill. The 
rollers (6) evenly spaced in the head are kept by a separator (13) and protected by a cover (12). The rollers and head that are heated during rolling are cooled by a cooling system consisting of a copper cooler (11) filled with cooling liquid (20). The cooling liquid circulates gravitative around partition (19) under the influence of the difference coolant temperature. The heat from the cooler (11) is collected by an air stream generated by a fan (9) connected to the head (5). The airflow through the fan with spiral blades (10) takes place automatically during the spinning of the head because the air inlet is on a smaller spinning radius than the outlet. Arrows show the directions of flow of coolant and air in fig. 7.

The complete cycle of the device illustrated in Fig. 7 is as follows. With the head (5) raised, the pick (1) is inserted into the tubular guide (2), in which it rests on the pressure spring (3). The head of the pick shaft is heated to the softening temperature of the material, and then the tip (4) is inserted into the seat (1b). The lowered head (5) presses the pick through the rollers (6), which causes the springs (3) and (22) to bend and the jaws (7) (protected by the cover (16)) to be clamped on the pick. The pick is firmly immobilized by teeth (7a) cut on the inner surface of the jaws (7). The loose connection with cylindrical inlets (15) protects against the rotation of the jaws while allowing their movement along the cone of the hull (14) (fixed to the base (17) with pins (18)). The rotation of the head (5) with increasing longitudinal pressure causes a permanent seating of the tip by rolling the softened material of the head (1a) of the pick shaft.

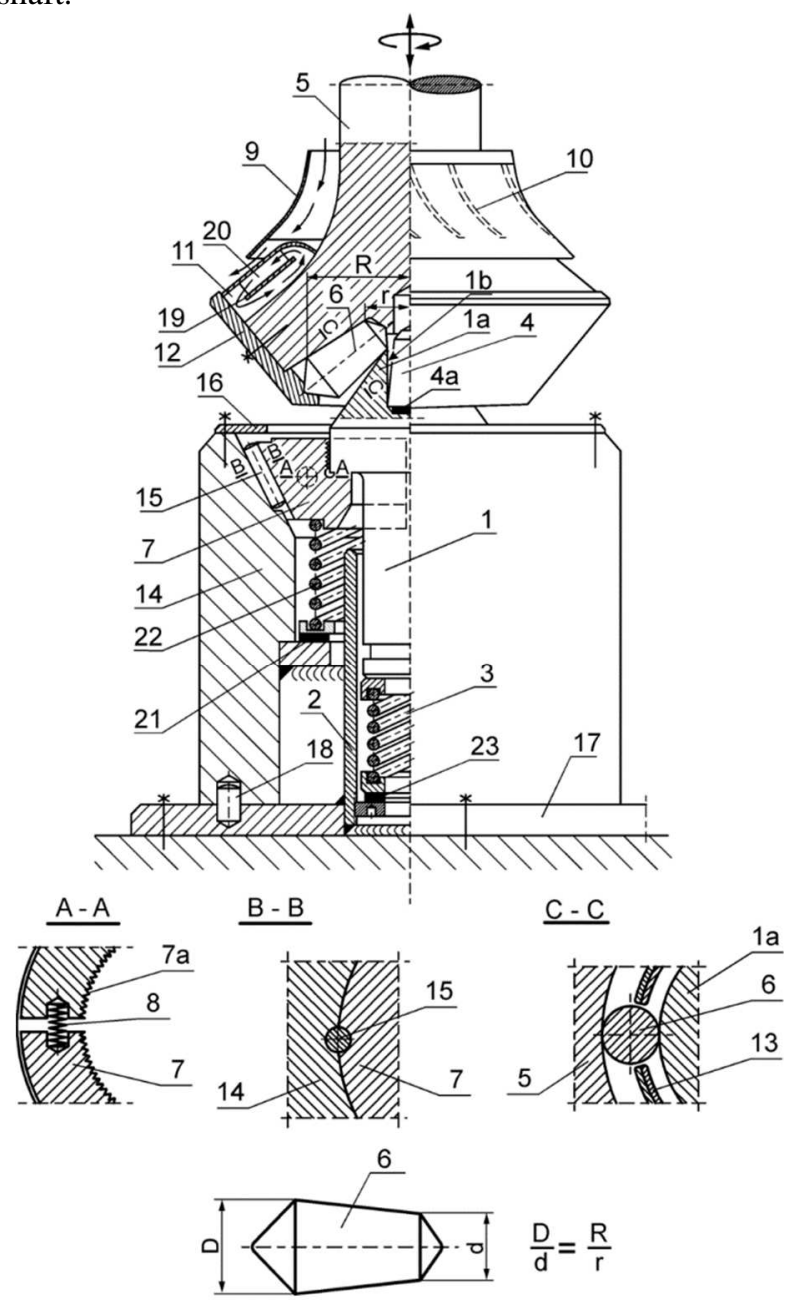

Fig. 7. Device for fixing tips of point-attack picks by rolling (description in the text)

After rolling the tip, the head (5) with the rollers (6) is lifted upwards while maintaining rotation for cooling the rollers and the head. The spring (22) then releases the pressure of the jaws (7), which open under the action of the spring (8). The tensioned spring (3) carries up the pick, which can be easily removed, and in its place, another pick is inserted, for which the whole process is repeated, as described previously. Washers (21) and (23) are used to adjust spring tension (3) and (22).

Cooling down after rolling, the material of the head of the pick shaft shrinks on the tip to further strengthen the connection. It is possible to increase thermal shrinkage efficiency by cooling the tip before inserting it into the seat in the pick shaft. Alternatively, it is possible to insert a thin metal disc (4a), for example, brass, into the bottom of the seat before placing the tip into it, to ease the distribution of tip contact pressure on the bottom of the seat. 
This reduces the risk of brittle cracks in the tip from pressures caused by high impact loads of the impact pick when cutting very hard rocks.

The plastic deformation of the head of the pick shaft can be additionally used to carry out the strengthening process by thermo-mechanical treatment. Heat-mechanical treatment increases the strength, hardness and resistance to abrasive wear of steel (Dobrzański, 2007). To fully use the effects of heat-mechanical treatment, it is necessary to choose the appropriate degree of heating, time and pace of rolling, and the right course of the cooling process after rolling the tips. Then it may be helpful to use additional cooling of the rolled zone of the picks, e.g. with an adjustable air stream. These parameters should be selected in the course of practical tests to obtain the best thermal-mechanical treatment effect. This creates additional opportunities to improve conical picks' performance, impossible to achieve with the currently used brazing of tips.

The use of the described method of mounting the tips and the device for its implementation allows obtaining significant effects in terms of improving the durability and reliability of picks at low costs, low energy consumption and solder savings. Any machine tool with a vertical spindle can be adapted to perform the procedure using the device described. This does not require significant investment outlays.

\section{Conclusions}

One of the reasons for accelerated operational damage to mining machines conical picks is blocking the rotation of the picks around their axis during cutting. The resulting unsymmetrical wear of the picks increases the cut's energy consumption and increases the risk of fatigue fractures of the pick shafts. Improving the rotation conditions of the picks and increasing the resistance to fatigue cracking of the pick shafts can be obtained through the structural modifications described in this paper. By using an adapter ring with suitably shaped mechanical properties (which is an integral part of the pick), it is possible to provide the required high resistance to contact pressure and reduce the resistance of movement of the pick relative to the associated pick holder during the pick rotation. These rings can be made of alloy steel subjected to appropriate heat and thermochemical treatment or sintered materials containing additives reducing friction coefficient. The physicochemical properties of these rings can thus be shaped separately from the pick shafts. A significant advantage resulting from the use of adapter rings is the possibility of significantly increasing the radius of the transition of the shank of the pick shaft into the shoulder. The transition can be with a constant or even better - variable radius. This results in a significant improvement in the fatigue life of the pick shafts in this sensitive zone, thanks to the reduction of the impact of the geometric notch. This will reduce the phenomenon of fatigue fracture of the pick shafts, which is not an isolated phenomenon at all.

Fastening the adapter ring by rolling the edge part of the shoulder on it is durable and reliable. Appropriate shaping of this ring's contact surface with the face of the pick holder or sleeve limits the penetration of the pick seat in the pick holder by water with a dust suspension, which prevents blocking of the pick in the pick holder that making impossible its rotation.

The method of fastening tips to conical picks proposed in this article by hot rolling has many useful advantages. It eliminates the need for the solder to connect tips with pick shanks. As indicated by observations in operating conditions, these elements' soldered connection does not meet the durability requirements. This applies particularly to picks intended for hard rock cutting, exposed to high temperatures, which may lead to softening or even melting of solder and the strong abrasive impact of the rock being mined and spoil. The developed fastening of the pick tips with their shafts is inseparable throughout the entire life of the picks, even in the event of high abrasive wear of the head of their shafts. It is a positive fitting connection with the use of the effect of thermal shrinkage. The device described in this work cooperating with typical machine tools with a vertical spindle can be used to perform the rolling operation of the picks.

Modifications to the construction and technology of conical (point-attack) picks presented in this paper contribute to a significant reduction in their wear and tear intensity, especially in the case of hard rock mining. The developed technology for manufacturing picks with a modified design does not cause a significant increase in investment outlays and costs of producing picks for mining machines.

\section{References}

Bołoz, Ł. (2019). Directions for increasing conical picks' durability. New Trends in Production Engineering, 2(1): 277-286, DOI: 10.2478/ntpe-2019-0029.

Cheluszka, P. and Mikuła, S. (2019). Method for fastening of a pick in the pick tool holder of a mining shearer machine and the device for industrial lapping of the shearer machine tool picks. Patent PL234422.

Cheluszka, P., Mikuła, S. and Mikuła, J. (2019). The use of burnishing process to improve the durability of steel body of picks of mining machines. Polish Mining Review, 75(12): 38-45. 
Choi, S.-W., Lee, C., Ha, T., Kang, T.-H. and Chang, S.-H. (2017). Endurance performance of conical picks with hardfacing for improving wear resistance. In: M. Hudyma and Y. Potvin (eds.), Proceedings of the First International Conference on Underground Mining Technology, Australian Centre for Geomechanics, Perth: 637-643, DOI: https://doi.org/10.36487/ACG_rep/1710_52_Choi.

Dąbrowski, Z. (2013). Wały maszynowe. Wydawnictwo Naukowe PWN, Warszawa.

Dewangan, S. and Chattopadhyaya, S. (2016). Characterization of wear mechanisms in distorted conical picks after coal cutting. Rock Mechanics and Rock Engineering, 49: 225-242, DOI: 10.1007/s00603-015-0726$\mathrm{x}$.

Dewangan, S., Chattopadhyaya, S. and Hloch, S. (2015). Wear assessment of conical pick used in coal cutting operation. Rock Mechanics and Rock Engineering, 48: 2129-2139, DOI: 10.1007/s00603-014-0680-z.

Dobrzański, L. (2007). Podstawy kształtowania struktury i własności materiałów metalowych. Wydawnictwo Politechniki Śląskiej, Gliwice.

García, J., Collado Ciprés, V., Blomqvist, A. and Kaplan, B. (2019). Cemented carbide microstructures: a review. International Journal of Refractory Metals \& Hard Materials, 80: 40-68, DOI: https://doi.org/10.1016/J.IJRMHM.2018.12.004.

Gehring, K.H. and Reumüller, B. (2002). Hard rock cutting with roadheaders - the ICUTROC approach. Proceedings of the $5^{\text {th }}$ NARMS and the $17^{\text {th }}$ TAC Conference: Mining and tunnelling innovation and opportunity, Toronto: 1637-1648.

Jonak, J. (1998). Teoretyczne podstawy urabiania skał stożkowymi nożami obrotowymi. Wydawnictwo Uczelniane Politechniki Lubelskiej, Lublin.

Jonak, J. (2011). Problems of automation and robotization of working machines. Polish Mining Review, 67(11): $1-8$.

Komatsu information materials [https://mining.komatsu/product-details/joy-js-series-bit-holder-cutting-system] (Access Date: 24.03.2020)

Kotwica, K. (2010). Effect of selected working conditions of cutting picks on their wear during the mining of hard rocks. Mechanics and Control, 29(3): 110-118.

Kotwica, K. (2012). Zastosowanie wspomagania wodnego w procesie urabiania skał narzędziami górniczymi. Wydawnictwo AGH, Kraków.

Krauze, K., Skowronek, T. and Mucha, K. (2016). Influence of the hard-faced layer welded on tangential-rotary pick operational part on to its wear rate. Archives of Mining Sciences, 61(4): 779-792, DOI: 10.1515/amsc2016-0053.

Li, X.S., Tiryaki, B. and Cleary, P.W. (2011). Hard rock cutting with smart*cut technology. Proceedings of the $22^{\text {nd }}$ World Mining Congress and Expo, Istanbul, Turkey: 725-732, DOI: 10.13140/2.1.4381.0885.

Liu, X., Liu, S., Li, L. and Cui, X. (2015). Experiment on conical pick cutting rock material assisted with front and rear water jet. Advances in Materials Science and Engineering, 2015(506579): 9, DOI: http://dx.doi.org/10.1155/2015/506579.

Lu, Z., Wan, L., Zeng, Q., Zhang, X. and Gao, K. (2018). The structural optimization of roadheader conical picks based on fatigue life. International Journal of Modeling, Simulation, and Scientific Computing, 9(2), 1850013, DOI: https://doi.org/10.1142/S1793962318500137.

Luo, Y., Zhang, D., Wang, Q., Liu, H., Cheng, G. and Ge, S. (2010). Preparation and properties of a new cutting pick of coal shearers. Mining Science and Technology, 20(5): 794-796, DOI: https://doi.org/10.1016/S1674-5264(09)60283-0.

Mu, H. and Min, L. (2009). Pick steel body of lamination layer mining machine. Patent CN201215017Y

Park, J.Y., Kang, H., Lee, J.W., Kim, J.H., Oh, J.Y., Cho, J.W., Rostami, J. and Kim, H.D. (2018). A study on rock cutting efficiency and structural stability of a point attack pick cutter by lab-scale linear cutting machine testing and finite element analysis. International Journal of Rock Mechanics and Mining Sciences, 103: 215-229, DOI: https://doi.org/10.1016/j.ijrmms.2018.01.034.

Prokopenko, S., Li, A., Kurzina, I. and Sushko, A. (2016). Improved operating performance of mining machine picks. IOP Conf. Series: Materials Science and Engineering, 142(012115): 8, DOI:10.1088/1757899X/142/1/012115.

Prokopenko, S.A., Vorobiev, A., Andreeva, L. and Janočko, J. (2018). Waste cutters utilization in underground coal mining. Acta Montanistica Slovaca, 23(1): 81-89.

Restner, U., Pichler, J. and Reumueller, B. (2007). New technologies extend the range of applications of roadheaders. Proceeding of the Symposium on Innovations in Tunnelling, Swiss Federal Institute of Technology Zurich, Zürich, Switzerland: 18.

Rock Straight System - Hard Rock Longwall Mining System for Low Seam Deposits. Caterpillar 2016 [https://s7d2.scene7.com/is/content/Caterpillar/CM20141006-57738-39286] (Access Date: 27.03.2020).

Sarwary, E. and Hagan, P. (2015). Changes in cutter performance with tool wear. Proceedings of the $15^{\text {th }}$ Coal Operators' Conference, University of Wollongong, The Australasian Institute of Mining and Metallurgy and Mine Managers Association of Australia: 283-290. 
Singh, S.P., Alam, T. and Chattopadhyaya, S. (2013). A review on the excavator tool bits wear. Proceedings of the 1st International and 16th National Conference on Machines and Mechanisms (iNaCoMM2013), IIT Roorkee, India: 823-829.

Tiryaki ,B. (2004). In situ studies on service life and pick consumption characteristics of shearer drums. The Journal of The South African Institute of Mining and Metallurgy, 104(2): 107-122.

Underground Mining - Kennametal product catalogue [https://www.kennametal.com/ content/dam/kennametal/kennametal/common/Resources/Catalogs-Literature/Mining/B-1202961_KMT_UGM13_EN_LR.pdf] (Access Date: 27.03.2020).

Vogt, D. (2016). A review of rock cutting for underground mining: past, present, and future. Journal of the Southern African Institute of Mining and Metallurgy, 116(11): 1011-1026, DOI: http://dx.doi.org/10.17159/2411-9717/2016/v116n11a3.

https://www.jyfmachinery.com/product/u85-u85hd-style-cutting-picks-fitting-underground-mining-and-surfacemining/ (Access Date: 24.03.2020).

https://www.jyfmachinery.com/product/ts30c-cutting-picks-fitting-underground-mining-and-surface-mining/ (Access Date: 24.03.2020).

https://www.engineerlive.com/content/mining-hard-rock-longwall-efficiency (Access Date: 27.03.2020). 